\title{
Unanswered Questions in the Genetic Basis of Primary Aldosteronism
}

Author

Ute I. Scholl

\author{
Affiliation \\ Department of Nephrology, Medical School, Heinrich Heine \\ University, University Hospital Düsseldorf, Düsseldorf, \\ Germany \\ Key words \\ aldosterone-producing adenoma, bilateral adrenal \\ hyperplasia, genetics, familial hyperaldosteronism \\ received 04.09 .2017 \\ accepted 14.09.2017 \\ Bibliography \\ DOI https://doi.org/10.1055/s-0043-120066 \\ Published online: 24.10 .2017 \\ Horm Metab Res 2017; 49: 963-968 \\ (c) Georg Thieme Verlag KG Stuttgart · New York \\ ISSN 0018-5043 \\ Correspondence \\ Ute I. Scholl M.D. \\ Department of Nephrology \\ Medical School \\ Heinrich Heine University \\ Moorenstraße 5 \\ 40225 Düsseldorf \\ Germany \\ Tel.: +49/211/81 04086, Fax: +49/211/8101504086 \\ ute.scholl@med.uni-duesseldorf.de
}

\section{ABSTRACT}

Over the past six years, the genetic basis of a significant fraction of primary aldosteronism (PA) cases has been solved. Breakthrough discoveries include the role of somatic variants in the KCNJ5, CACNA1D, ATP1A1, and ATP2B3 genes as causes of aldosterone-producing adenomas (APAs), and the recognition of three novel hyperaldosteronism syndromes with germline variants in the KCNJ5, CACNA1D, and CACNA1H genes. The description of somatic variants in CACNA1D and ATP1A1 in aldosterone-producing cell clusters (APCCs) suggests that these clusters are precursors of some aldosterone-producing adenomas. Yet, a number of questions remain unanswered. These include the genetic basis of about $40 \%$ of APAs without somatic variants in known genes. Do technical issues explain this finding, or are the unexplained APAs due to somatic copy number variation or rare variants in thus-far undiscovered genes? Similarly, the role of CTNNB1 (beta catenin) variants in APA pathogenesis is still unclear. The major question to be solved is the genetic basis of bilateral adrenal hyperplasia (BAH). Is BAH due to the bilateral occurrence of APCCs, to germline variants, or perhaps due to unknown serum factors? Lastly, the etiology of unsolved cases of apparently familial hyperaldosteronism remains to be discovered. It is expected that genetic studies over the next few years will lead to answers to at least some of the questions raised.

\section{Abbreviations}

ACTH Adrenocorticotropic hormone

APA Aldosterone-producing adenoma

APCC Aldosterone-producing cell clusters

ATP1A1 ATPase $\mathrm{Na}^{+} / \mathrm{K}^{+}$Transporting Subunit Alpha 1

ATP2B3 ATPase Plasma Membrane Ca ${ }^{2+}$ Transporting 3

$\mathrm{BAH} \quad$ Bilateral adrenal hyperplasia

CACNA1D Calcium channel, voltage-dependent, L type, alpha 1D subunit

CACNA1H Calcium channel, voltage-dependent, T type, alpha $1 \mathrm{H}$ subunit

CNV Copy number variation

CYP11B1 Cytochrome P450, family 11, subfamily B, polypeptide 1

CYP11B2 Cytochrome P450, family 11, subfamily B, polypeptide 2
FH Familial hyperaldosteronism

GRA Glucocorticoid-remediable aldosteronism

KCNJ5 Potassium channel, inwardly rectifying subfamily J, member 5

PA Primary aldosteronism

PASNA Primary aldosteronism, seizures, and neurologic abnormalities

SNV Single nucleotide polymorphism

\section{Introduction}

Primary aldosteronism (PA) is considered the most common cause of secondary hypertension. A recent study reported a prevalence of about $6 \%$ [1] in primary care, with higher prevalence among severely hypertensive cases. The prevalence in hypertension referral 
centers is about $6-10 \%$ [2-4]. PA is characterized by excessive production of the adrenal steroid hormone aldosterone despite suppressed levels of its upstream regulator, the aspartyl protease renin, and normal or low serum potassium levels. Aldosterone-producing adenomas (APAs, with single or multiple nodules [5]) account for about $30 \%$ of cases, and bilateral adrenal hyperplasia for about $60 \%$ [4]. Diffuse unilateral hyperplasia is less common [6], whereas malignancy [7] and familial hyperaldosteronism (FH) [8] are considered rare.

Major progress has been made in understanding the genetic basis of PA over the past six years, but many questions remain unanswered [9]. This brings to mind U.S. Secretary of Defense Donald Rumsfeld's famous statement: “...as we know, there are known knowns; there are things we know we know. We also know there are known unknowns; that is to say we know there are some things we do not know. But there are also unknown unknowns - the ones we don't know we don't know" [10]. These three aspects of the genetics of PA will be covered in this review.

\section{The Known Knowns}

About $40 \%$ of APAs are caused by one of two somatic (tumor specific) variants in the KCNJ5 gene, and other variants are very rare [11-13]. KCNJ5 encodes an inward rectifier potassium channel. The disease-causing variants are located within or close to the selectivity filter of the channel and cause abnormal sodium permeability. Sodium influx through mutant channels leads to cellular depolarization, activation of voltage-dependent calcium channels, calcium influx and activation of the pathways that regulate aldosterone production $[11,14]$. Approximately $10 \%$ of tumors carry somatic variants in the CACNA1D gene, encoding a voltage-gated calcium channel $[13,15,16]$. These variants directly cause increased calcium influx through the mutant channel. Mutations in the $\mathrm{Na}^{+} / \mathrm{K}^{+}$ATPase subunit gene ATP1A1 account for approximately $5 \%$ of tumors, and mutations in the plasma membrane $\mathrm{Ca}^{2+}$ ATPase gene ATP2B3 for a small percentage (about $2 \%$ ) $[13,16,17]$. These variants cause abnormal permeability to sodium or proton ions, leading to depolarization similar to KCNJ5 mutations $[16,18]$. Lastly, mutations in the CTNNB1 gene encoding beta catenin are found in $2-5 \%$ of tumors [19-21].

Important insight into the origin of APAs came from the description of subcapsular aldosterone-producing cell clusters (APCCs) that are found in normal adult adrenal glands. These clusters also carry somatic variants in the CACNA1D and ATP1A1 genes [22] ( $\vee$ Fig. 1), suggesting that they represent precursors of APAs carrying such variants [23].

Familial aggregation of primary aldosteronism was initially reported in a father and his son with glucocorticoid-remediable aldosteronism (GRA, FH-I) [24]. GRA is due to unequal cross over between CYP11B1, encoding 11 $\beta$-hydroxylase involved in cortisol production under the control of adrenocorticotropic hormone (ACTH), and CYP11B2, encoding aldosterone synthase [25]. This leads to ACTH-dependent aldosterone production in the zona fasciculata. Following the discovery of somatic KCNJ5 and CACNA1D mutations in APAs, inherited or de novo germline variants in the same genes were identified in FH-III $[11,26,27]$ and PA with seizures and neurologic abnormalities (PASNA) syndrome [15], respectively. Lastly, germline CACNA1H variants, which cause gain of function of the encoded calcium channel, were discovered in FH-IV [28].

\section{The Known Unknowns}

Despite the significant progress in understanding PA, several questions remain unanswered. One of the most obvious "known" questions is the genetic basis of the about $40 \%$ of aldosterone-producing adenomas without mutations in KCNJ5, CACNA1D, ATP1A1, $A T P 2 B 3$, and CTNNB1. Several not mutually exclusive explanations come to mind.

The first explanation is of technical nature. APAs can demonstrate intra-tumor heterogeneity. Some tumor areas can be positive for aldosterone synthase expression by immunohistochemistry, whereas others are not, and variants are only found in aldosterone synthase positive areas [29]. Because not all tumor areas may carry disease-causing variants and biopsies can be contaminated with surrounding normal tissue and/or stroma, variant allele frequencies can be below Sanger sequencing detection levels. This explains why variants are occasionally found by next-generation sequencing in tumors that are negative by Sanger sequencing [19]. Analysis of large genes with variants scattered throughout the gene, such as CACNA1D, is particularly challenging by Sanger sequencing, and many studies have only analyzed part of the gene, so mutation frequencies may have been underestimated. APAs are also not always single circumscribed tumors. Surrounding hyperplasia and multinodular glands have also been described $[5,19]$, and in the absence of aldosterone synthase immunohistochemistry, it can be difficult to distinguish non-producing nodules from those producing aldosterone. Taken together, studies performed on tissue biopsies without immunohistochemistry against aldosterone synthase may have underestimated "true" mutation frequencies.

The second explanation would be that variants in additional genes that are only mutated in a small fraction of samples have so far evaded detection by exome sequencing. One would expect the finding of recurrent variants in the same gene in at least two independent tumor samples to support a role in pathogenesis. If mutations in an unknown gene are present in $5 \%$ of the samples, the binomial probability of finding mutations in at least two samples (assuming perfect sensitivity of the assay) is about $96 \%$ when 100 samples are sequenced. This likelihood drops to $72 \%$ with 50 samples sequenced, and $36 \%$ with 25 samples sequenced. These considerations suggest that a meta-analysis of exome sequencing studies from different groups may reveal additional genes involved in APA pathogenesis.

Third, copy number variation (CNV) has been described in APAs [11], but its role in the pathophysiology of APAs remains unclear. CNV may well account for a fraction of APAs, and the identification of one or several overlapping areas of CNV between tumors may point to key pathways involved in aldosterone production and/or proliferation. Another possibility is the co-occurrence of predisposing single-nucleotide variants (SNVs) in the germline and CNV in corresponding tumor samples - adrenals with several APAs and/or accompanying hyperplasia might be good candidates for such a disease mechanism. 


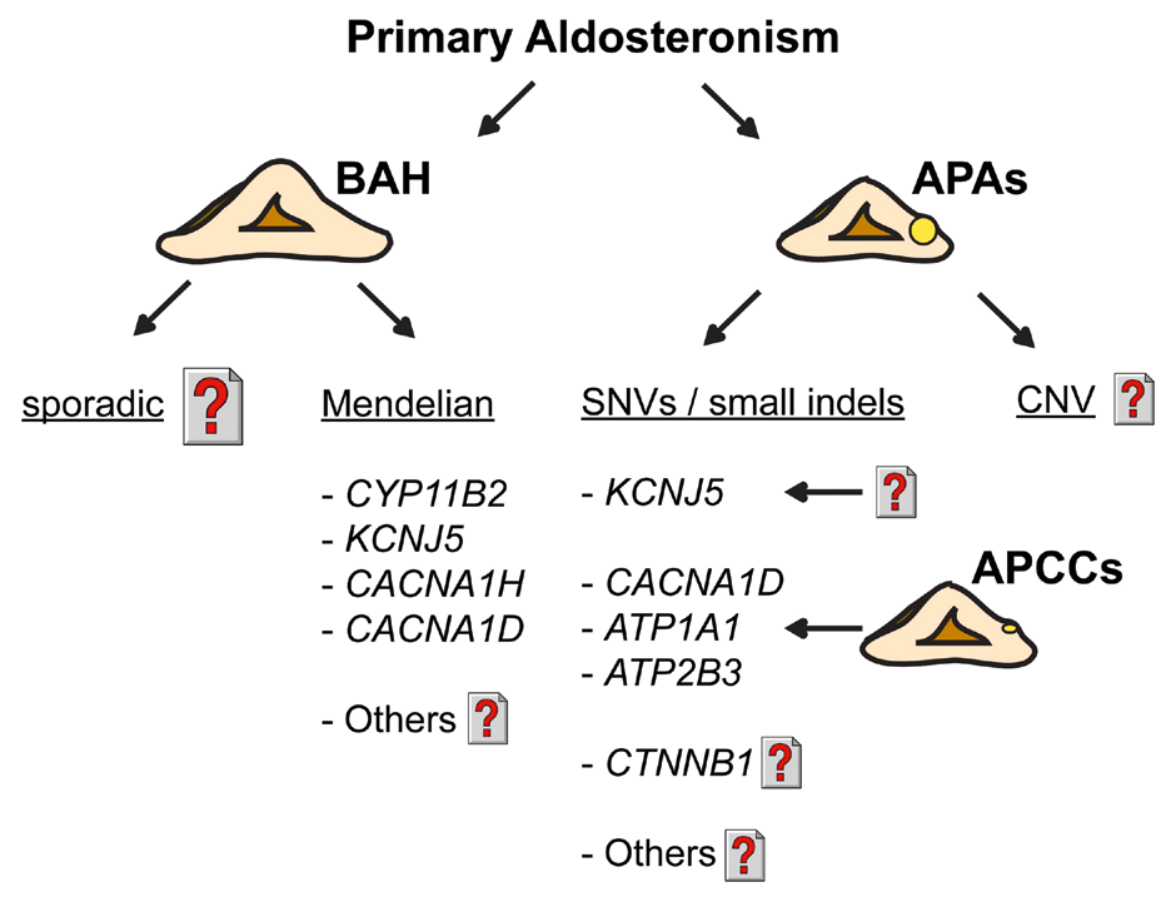

- Fig. 1 Genetics of PA - Open Questions: The genetic basis of sporadic bilateral adrenal hyperplasia (BAH) is unsolved. In addition to known Mendelian forms PA, there likely are several unknown syndromes to be discovered. Several genes show somatic single nucleotide variants (SNVs) or small insertions/deletions (indels) in aldosterone-producing adenomas (APAs). Some of these tumors likely arise from aldosterone-producing cell clusters (APCCs), but the origin of KCNJ5 mutation-positive tumors, the largest subgroup, is unsolved. Similarly, the role of CTNNB1 variants in APAs remains unclear. There are likely variants in additional genes to be discovered, and the role of copy-number variation (CNV) in APAs also remains to be characterized.

Another open question is the role of CTNNB1 mutations in APAs. It is stunning that CTNNB1 variants are found in non-producing adrenal adenomas, adrenocortical carcinomas, cortisol-producing adenomas as well as APAs [19-21, 30-34]. Some cortisol-producing adenomas with CTNNB1 variants show additional GNAS variants, which explain hormone production [34,35], but so far, no mutations in second genes have been described in APAs with CTNNB1 variants. One group suggested an association of APAs with CTNNB1 mutations with pregnancy, presumably due to expression and activation of gonadal receptors [36], but this seems highly unlikely because about $25 \%$ of CTNNB1-positive tumors occur in males, and because these variants are more common in post-menopausal females than in pregnant women $[20,21,37]$. Similarly, expression of gonadal receptors as well as CYP11B2 was subsequently shown to be heterogeneous [21]. Taken together, these findings suggest that CTNNB1 variants may cause adrenal proliferation by activating Wnt signaling, but not excessive hormone production. The factors driving aldosterone production remain to be discovered.

Lastly, open questions concern the origin of KCNJ5-positive tumors. It has been suggested early on and confirmed that these tumors are histologically different from tumors with mutations in other genes; they tend to have a more fasciculata-like appearance $[16,19,38]$. It is therefore interesting that $K C N J 5$ variants are not found in APCCs [22]. Do KCNJ5-positive tumors arise from zona fasciculata [38]? Do they grow so fast that precursors evade detection as APCCs? Related to this question, it is unclear why KCNJ5 muta- tions are more prevalent in females than in males in European and some Asian cohorts [12]. A higher mutation rate seems unlikely given that such female preponderance is absent in those with other mutations $[13,17]$. An effect of gonadal steroids on proliferation or hormone production may play a role.

Another area of „known unknowns“ is the genetic basis of $\mathrm{FH}$. There are a number of unsolved kindreds and/or cases. These include an extended kindred with so-called FH-II (non-glucocorticoid remediable aldosteronism) described in 1992 [39, 40], but also many additional cases of childhood-onset PA. In one analysis, a CACNA1H variant was identified in five of 40 unrelated subjects with hypertension due to PA by age 10 years [28], yet the remaining cases are unsolved. Whereas there is no proof that aldosteronism in these cases is Mendelian, the index of suspicion is high. APAs are increasingly rare in the pediatric age range, as is sporadic bilateral adrenal hyperplasia. These observations suggest that there are likely additional genes to be discovered in FH. Incomplete penetrance, small kindreds and the presence of phenocopies (subjects with sporadic PA in the family) are potential challenges in the analysis.

\section{The Unknown Unknowns}

The major "unknown unknown" is a potential genetic basis of sporadic $\mathrm{BAH}$, also known as idiopathic hyperaldosteronism. Patients with $\mathrm{BAH}$ may show nodular changes on adrenal CT imaging, or CT 
may be normal [4]. Because these patients typically do not undergo surgery, $\mathrm{BAH}$ is a histologically ill-defined entity. If the diagnosis is based on adrenal venous sampling showing bilateral aldosterone production [4], potential correlations may include bilateral microscopic hyperplasia, bilateral nodular hyperplasia, bilateral adenomas [41, 42], bilateral APCCs or any combination of these entities.

Thus, genetic contributions could include somatic variants in adenomas or APCCs, or predisposing germline variants. Nongenetic causes may include hypothetical serum factors or autoantibodies against the angiotensin II type 1 receptor [43].

How could potential genetic contributors be studied? One approach would be to perform next-generation sequencing of lesions in the rare cases that have undergone surgery and search for somatic variants [42]. This may include cases operated based on presumed lateralization without cure [44]. Another option would be to study adrenals from autopsies - perhaps patients with known $\mathrm{BAH}$ could be part of a study that involves post-mortem removal of adrenal glands, or autopsy cases with $\mathrm{BAH}$ positive for aldosterone synthase expression could be studied. A case report suggests that elevated aldosterone levels can be determined from postmortem blood [45], although reference ranges would have to be determined. Post mortem urinary aldosterone may also prove useful. Perhaps assessment of the juxtaglomerular apparatus could serve to distinguish primary from secondary aldosteronism [46]. Regarding potential germline variants, whether genome-wide association studies (GWAS) or next-generation sequencing studies would be helpful remains to be determined. Prior GWAS studies have focused on aldosterone to renin ratio in a population-based cohort (not PA) [47] or candidate gene association with aldosterone levels [48].

\section{Outlook}

The expected progress in solving unanswered questions in the genetic basis of PA over the next few years seems straightforward regarding the "known unknowns". We will likely see the discovery of genetic variants in one or several additional genes that explain a small fraction of APAs, and we will likely see a better characterization of CNVs in APAs. This is expected to result in new insight into the pathophysiology of APAs and PA. We should also anticipate the discovery of variants in (a) new gene(s) in $\mathrm{FH}$, with similar pathophysiological implications. Future animal models may help to better understand the development of KCNJ5-mutant tumors.

Much more difficult to predict is the progress on the genetic basis of bilateral adrenal hyperplasia, although a contribution of somatic variants seems possible. In any case, the exciting times of genetic discoveries in PA will likely continue.

\section{Acknowledgements}

U.I.S. is supported by grants of the Ministerium für Kultur und Wissenschaft des Landes Nordrhein-Westfalen, Germany (NRW-Rückkehrprogramm, Junges Kolleg), the Deutsche Forschungsgemeinschaft (SCHO 1386/2-1) and the Fritz Thyssen Stiftung (10.16.1.027MN).
Conflict of Interest

The author is listed as an inventor on a patent application by Yale University (Compositions and Methods for Diagnosing and Treating Diseases and Disorders Associated with Mutant KCNJ5).

\section{References}

[1] Monticone S, Burrello J, Tizzani D, Bertello C, Viola A, Buffolo F, Gabetti L, Mengozzi G, Williams TA, Rabbia F, Veglio F, Mulatero P. Prevalence and clinical manifestations of primary aldosteronism encountered in primary care practice. J Am Coll Cardiol 2017; 69: $1811-1820$

[2] Rossi GP, Bernini G, Caliumi C, Desideri G, Fabris B, Ferri C, Ganzaroli C, Giacchetti G, Letizia C, Maccario M, Mallamaci F, Mannelli M, Mattarello MJ, Moretti A, Palumbo G, Parenti G, Porteri E, Semplicini A, Rizzoni D, Rossi E, Boscaro M, Pessina AC, Mantero F. A prospective study of the prevalence of primary aldosteronism in 1,125 hypertensive patients. I Am Coll Cardiol 2006; 48: 2293-2300

[3] Mosso L, Carvajal C, Gonzalez A, Barraza A, Avila F, Montero J, Huete A, Gederlini A, Fardella CE. Primary aldosteronism and hypertensive disease. Hypertension 2003; 42: 161-165

[4] Funder JW, Carey RM, Mantero F, Murad MH, Reincke M, Shibata H, Stowasser M, Young WF Jr.. The management of primary aldosteronism: case detection, diagnosis, and treatment: An endocrine society clinical practice guideline. J Clin Endocrinol Metab 2016; 101: 1889-1916

[5] Fernandes-Rosa FL, Giscos-Douriez I, Amar L, Gomez-Sanchez CE, Meatchi T, Boulkroun S, Zennaro MC. Different somatic mutations in multinodular adrenals with aldosterone-producing adenoma. Hypertension 2015; 66: 1014-1022

[6] lacobone M, Citton M, Viel G, Boetto R, Bonadio I, Tropea S, Mantero F, Rossi GP, Fassina A, Nitti D, Favia G. Unilateral adrenal hyperplasia: A novel cause of surgically correctable primary hyperaldosteronism. Surgery 2012; 152: 1248-1255

[7] Seccia TM, Fassina A, Nussdorfer GG, Pessina AC, Rossi GP. Aldosterone-producing adrenocortical carcinoma: an unusual cause of Conn's syndrome with an ominous clinical course. Endocr Relat Cancer 2005; 12: 149-159

[8] Korah HE, Scholl UI. An update on familial hyperaldosteronism. Horm Metab Res 2015; 47: 941-946

[9] Funder JW. Primary aldosteronism: New answers, new questions. Horm Metab Res 2015; 47: 935-940

[10] DoD News Briefing. February 12, 2002; http://archive.defense.gov/ Transcripts/Transcript.aspx?TranscriptID = 2636 . Accessed 09/03, 2017

[11] Choi M, Scholl UI, Yue P, Bjorklund P, Zhao B, Nelson-Williams C, Ji W, Cho Y, Patel A, Men CJ, Lolis E, Wisgerhof MV, Geller DS, Mane S, Hellman P, Westin G, Akerstrom G, Wang W, Carling T, Lifton RP. K+ channel mutations in adrenal aldosterone-producing adenomas and hereditary hypertension. Science 2011; 331: 768-772

[12] Lenzini L, Rossitto G, Maiolino G, Letizia C, Funder JW, Rossi GP. A Meta-Analysis of Somatic KCNJ5 K Channel Mutations In 1636 Patients with an aldosterone-producing adenoma. J Clin Endocrinol Metab 2015; jc20152149

[13] Fernandes-Rosa FL, Williams TA, Riester A, Steichen O, Beuschlein F, Boulkroun S, Strom TM, Monticone S, Amar L, Meatchi T, Mantero F, Cicala MV, Quinkler M, Fallo F, Allolio B, Bernini G, Maccario M, Giacchetti G, Jeunemaitre X, Mulatero P, Reincke M, Zennaro MC. Genetic spectrum and clinical correlates of somatic mutations in aldosterone-producing adenoma. Hypertension 2014; 64: 354-361

[14] Spat A, Hunyady L. Control of aldosterone secretion: A model for convergence in cellular signaling pathways. Physiol Rev 2004; 84: 489-539 
[15] Scholl UI, Goh G, Stolting G, de Oliveira RC, Choi M, Overton JD, Fonseca AL, Korah R, Starker LF, Kunstman JW, Prasad ML, Hartung EA, Mauras N, Benson MR, Brady T, Shapiro JR, Loring E, Nelson-Williams C, Libutti SK, Mane S, Hellman P, Westin G, Akerstrom G, Bjorklund P, Carling T, Fahlke C, Hidalgo P, Lifton RP. Somatic and germline CACNA1D calcium channel mutations in aldosterone-producing adenomas and primary aldosteronism. Nat Genet 2013; 45: 1050-1054

[16] Azizan EA, Poulsen H, Tuluc P, Zhou J, Clausen MV, Lieb A, Maniero C, Garg S, Bochukova EG, Zhao W, Shaikh LH, Brighton CA, Teo AE, Davenport AP, Dekkers T, Tops B, Kusters B, Ceral J, Yeo GS, Neogi SG, McFarlane I, Rosenfeld N, Marass F, Hadfield J, Margas W, Chaggar K, Solar M, Deinum J, Dolphin AC, Farooqi IS, Striessnig J, Nissen P, Brown MJ. Somatic mutations in ATP1A1 and CACNA1D underlie a common subtype of adrenal hypertension. Nat Genet 2013; 45: 1055-1060

[17] Beuschlein F, Boulkroun S, Osswald A, Wieland T, Nielsen HN, Lichtenauer UD, Penton D, Schack VR, Amar L, Fischer E, Walther A, Tauber P, Schwarzmayr T, Diener S, Graf E, Allolio B, Samson-Couterie $B$, Benecke A, Quinkler M, Fallo F, Plouin PF, Mantero F, Meitinger T, Mulatero P, Jeunemaitre X, Warth R, Vilsen B, Zennaro MC, Strom TM, Reincke M. Somatic mutations in ATP1A1 and ATP2B3 lead to aldosterone-producing adenomas and secondary hypertension. Nat Genet 2013; 45: 440-444

[18] Tauber P, Aichinger B, Christ C, Stindl J, Rhayem Y, Beuschlein F, Warth $R$, Bandulik S. Cellular Pathophysiology of an Adrenal Adenoma-Associated Mutant of the Plasma Membrane Ca(2+)-ATPase ATP2B3. Endocrinology 2016; 157: 2489-2499

[19] Scholl UI, Healy JM, Thiel A, Fonseca AL, Brown TC, Kunstman JW, Horne M], Dietrich D, Riemer J, Kucukkoylu S, Reimer EN, Reis AC, Goh G, Kristiansen G, Mahajan A, Korah R, Lifton RP, Prasad ML, Carling T. Novel somatic mutations in primary hyperaldosteronism are related to the clinical, radiological and pathological phenotype. Clin Endocrinol (Oxf) 2015; 83: 779-789

[20] Akerstrom T, Maharjan R, Sven Willenberg H, Cupisti K, Ip J, Moser A, Stalberg P, Robinson B, Alexander Iwen K, Dralle H, Walz MK, Lehnert $\mathrm{H}$, Sidhu S, Gomez-Sanchez C, Hellman P, Bjorklund P. Activating mutations in CTNNB1 in aldosterone producing adenomas. Sci Rep 2016; 6: 19546

[21] Wu VC, Wang SM, Chueh S], Yang SY, Huang KH, Lin YH, Wang J], Connolly R, Hu YH, Gomez-Sanchez CE, Peng KY, Wu KD. The prevalence of CTNNB1 mutations in primary aldosteronism and consequences for clinical outcomes. Sci Rep 2017; 7: 39121

[22] Nishimoto K, Tomlins SA, Kuick R, Cani AK, Giordano T], Hovelson DH, Liu CJ, Sanjanwala AR, Edwards MA, Gomez-Sanchez CE, Nanba K, Rainey WE. Aldosterone-stimulating somatic gene mutations are common in normal adrenal glands. Proc Natl Acad Sci U S A 2015; 112 : E4591-E4599

[23] Nishimoto K, Seki T, Kurihara I, Yokota K, Omura M, Nishikawa T, Shibata H, Kosaka T, Oya M, Suematsu M, Mukai K. Case report: Nodule development from subcapsular aldosterone-producing cell clusters causes hyperaldosteronism. J Clin Endocrinol Metab 2016; 101: 6-9

[24] Sutherland DJ, Ruse JL, Laidlaw JC. Hypertension, increased aldosterone secretion and low plasma renin activity relieved by dexamethasone. Can Med Assoc J 1966; 95: 1109-1119

[25] Lifton RP, Dluhy RG, Powers M, Rich GM, Cook S, Ulick S, Lalouel JM. A chimaeric 11 beta-hydroxylase/aldosterone synthase gene causes glucocorticoid-remediable aldosteronism and human hypertension. Nature 1992; 355: 262-265

[26] Scholl UI, Nelson-Williams C, Yue P, Grekin R, Wyatt R], Dillon M], Couch R, Hammer LK, Harley FL, Farhi A, Wang WH, Lifton RP. Hypertension with or without adrenal hyperplasia due to different inherited mutations in the potassium channel KCNJ5. Proc Natl Acad Sci U S A 2012; 109: 2533-2538
[27] Mulatero P, Tauber P, Zennaro MC, Monticone S, Lang K, Beuschlein F, Fischer E, Tizzani D, Pallauf A, Viola A, Amar L, Williams TA, Strom TM, Graf E, Bandulik S, Penton D, Plouin PF, Warth R, Allolio B, Jeunemaitre $\mathrm{X}$, Veglio F, Reincke M. KCNJ5 mutations in European families with nonglucocorticoid remediable familial hyperaldosteronism. Hypertension 2012; 59: 235-240

[28] Scholl UI, Stolting G, Nelson-Williams C, Vichot AA, Choi M, Loring E, Prasad ML, Goh G, Carling T, Juhlin CC, Quack I, Rump LC, Thiel A, Lande M, Frazier BG, Rasoulpour M, Bowlin DL, Sethna CB, Trachtman $\mathrm{H}$, Fahlke C, Lifton RP. Recurrent gain of function mutation in calcium channel CACNA1H causes early-onset hypertension with primary aldosteronism. eLife 2015; 4:

[29] Nanba K, Chen AX, Omata K, Vinco M, Giordano T], Else T, Hammer GD, Tomlins SA, Rainey WE. Molecular heterogeneity in aldosterone-producing adenomas. J Clin Endocrinol Metab 2016; 101: 999-1007

[30] Assie G, Letouze E, Fassnacht M, Jouinot A, Luscap W, Barreau O, Omeiri H, Rodriguez S, Perlemoine K, Rene-Corail F, Elarouci N, Sbiera S, Kroiss M, Allolio B, Waldmann J, Quinkler M, Mannelli M, Mantero F, Papathomas T, De Krijger R, Tabarin A, Kerlan V, Baudin E, Tissier F, Dousset B, Groussin L, Amar L, Clauser E, Bertagna X, Ragazzon B, Beuschlein F, Libe R, de Reynies A, Bertherat J. Integrated genomic characterization of adrenocortical carcinoma. Nat Genet 2014; 46: 607-612

[31] Bonnet S, Gaujoux S, Launay P, Baudry C, Chokri I, Ragazzon B, Libe R, Rene-Corail F, Audebourg A, Vacher-Lavenu MC, Groussin L, Bertagna $X$, Dousset B, Bertherat J, Tissier F. Wnt/beta-catenin pathway activation in adrenocortical adenomas is frequently due to somatic CTNNB1-activating mutations, which are associated with larger and nonsecreting tumors: a study in cortisol-secreting and -nonsecreting tumors. J Clin Endocrinol Metab 2011; 96: E419-E426

[32] Goh G, Scholl UI, Healy JM, Choi M, Prasad ML, Nelson-Williams C, Kunstman JW, Korah R, Suttorp AC, Dietrich D, Haase M, Willenberg HS, Stalberg P, Hellman P, Akerstrom G, Bjorklund P, Carling T, Lifton RP. Recurrent activating mutation in PRKACA in cortisol-producing adrenal tumors. Nat Genet 2014; 46: 613-617

[33] Juhlin CC, Goh G, Healy JM, Fonseca AL, Scholl UI, Stenman A, Kunstman JW, Brown TC, Overton JD, Mane SM, Nelson-Williams C, Backdahl M, Suttorp AC, Haase M, Choi M, Schlessinger J, Rimm DL, Hoog A, Prasad ML, Korah R, Larsson C, Lifton RP, Carling T. Whole-exome sequencing characterizes the landscape of somatic mutations and copy number alterations in adrenocortical carcinoma. J Clin Endocrinol Metab 2015; 100: E493-E502

[34] Thiel A, Reis AC, Haase M, Goh G, Schott M, Willenberg HS, Scholl UI. PRKACA mutations in cortisol-producing adenomas and adrenal hyperplasia: a single-center study of 60 cases. Eur J Endocrinol 2015; 172: 677-685

[35] Cao Y, He M, Gao Z, Peng Y, Li Y, Li L, Zhou W, Li X, Zhong X, Lei Y, Su T, Wang $\mathrm{H}$, Jiang $Y$, Yang L, Wei W, Yang $X$, Jiang $X$, Liu L, He J, Ye J, Wei Q, Li Y, Wang W, Wang J, Ning G. Activating hotspot L205R mutation in PRKACA and adrenal Cushing's syndrome. Science 2014; 344: 913-917

[36] Teo AE, Garg S, Haris Shaikh L, Zhou J, Karet Frankl FE, Gurnell M, Happerfield L, Marker A, Bienz M, Azizan EA, Brown MJ. Pregnancy, Primary Aldosteronism, and Adrenal CTNNB1 Mutations. N Engl J Med 2015; 373: 1429-1436

[37] Murtha TD, Carling T, Scholl UI. Pregnancy, Primary Aldosteronism, and Somatic CTNNB1 Mutations. N Engl J Med 2016; 374: 1492-1493

[38] Azizan EA, Lam BY, Newhouse S], Zhou J, Kuc RE, Clarke J, Happerfield L, Marker A, Hoffman G], Brown MJ. Microarray, qPCR, and KCNJ5 sequencing of aldosterone-producing adenomas reveal differences in genotype and phenotype between zona glomerulosa- and zona fasciculata-like tumors. J Clin Endocrinol Metab 2012; 97: E819-E829 
[39] Stowasser M, Gordon RD, Tunny T], Klemm SA, Finn WL, Krek AL. Familial hyperaldosteronism type II: five families with a new variety of primary aldosteronism. Clin Exp Pharmacol Physiol 1992; 19: 319-322

[40] Sukor N, Mulatero P, Gordon RD, So A, Duffy D, Bertello C, Kelemen L, Jeske Y, Veglio F, Stowasser M. Further evidence for linkage of familial hyperaldosteronism type II at chromosome 7p22 in Italian as well as Australian and South American families. J Hypertens 2008; 26: 1577-1582

[41] Morimoto R, Satani N, Iwakura Y, Ono Y, Kudo M, Nezu M, Omata K, Tezuka Y, Seiji K, Ota H, Kawasaki Y, Ishidoya S, Nakamura Y, Arai Y, Takase K, Sasano H, Ito S, Satoh F. A case of bilateral aldosterone-producing adenomas differentiated by segmental adrenal venous sampling for bilateral adrenal sparing surgery. J Hum Hypertens 2016; 30: 379-385

[42] Wu VC, Chueh SC, Chang HW, Lin WC, Liu KL, Li HY, Lin YH, Wu KD, Hsieh BS. Bilateral aldosterone-producing adenomas: Differentiation from bilateral adrenal hyperplasia. QJM 2008; 101: 13-22

[43] Li H, Yu X, Cicala MV, Mantero F, Benbrook A, Veitla V, Cunningham MW, Kem DC. Prevalence of angiotensin II type 1 receptor (AT1R)activating autoantibodies in primary aldosteronism. J Am Soc Hypertens 2015; 9: 15-20

[44] Williams TA, Lenders JWM, Mulatero P, Burrello J, Rottenkolber M, Adolf C, Satoh F, Amar L, Quinkler M, Deinum J, Beuschlein F, Kitamoto KK, Pham U, Morimoto R, Umakoshi H, Prejbisz A, Kocjan T, Naruse M, Stowasser M, Nishikawa T, Young WF Jr., Gomez-Sanchez CE, Funder JW, Reincke M.Primary Aldosteronism Surgery Outcome i. Outcomes after adrenalectomy for unilateral primary aldosteronism: an international consensus on outcome measures and analysis of remission rates in an international cohort. Lancet Diabetes Endocrinol 2017; 5: 689-699

[45] Palmiere C, Lesta Mdel M, Sabatasso S, Mangin P, Augsburger M, Sporkert $\mathrm{F}$. Usefulness of postmortem biochemistry in forensic pathology: Illustrative case reports. Leg Med (Tokyo) 2012; 14: 27-35

[46] Parker RA. Distribution of the changes in the juxtaglomerular apparatus in human renal artery stenosis. Nephron 1967; 4: 315-325

[47] Spyroglou A, Bozoglu T, Rawal R, De Leonardis F, Sterner C, Boulkroun S, Benecke AG, Monti L, Zennaro MC, Petersen AK, Doring A, Rossi A, Bidlingmaier M, Warth R, Gieger C, Reincke M, Beuschlein F. Diastrophic dysplasia sulfate transporter (SLC26A2) is expressed in the adrenal cortex and regulates aldosterone secretion. Hypertension 2014; 63: 1102-1109

[48] Manichaikul A, Rich SS, Allison MA, Guagliardo NA, Bayliss DA, Carey RM, Barrett PQ. KCNK3 variants are associated with hyperaldosteronism and hypertension. Hypertension 2016; 68: 356-364 